\title{
Aula Inaugural do Presidente Emílio Garrastazu Médici na Escola Superior de Guerra
}

"As palavras que trago a esta casa, a que a generosidade de seu comandante chamou, para honra minha, de aula inaugural dos cursos de 1970, situam-se entre duas entregas de medalhas: a medalha por mim recebida do comandante desta Escola, e as que vou entregar ao Presidente Dutra, ao Marechal Obino e ao Marechal Cordeiro de Farias.

Nesta Escola e perante o seu criador, - Marechal Dutra, minhas palavras ficam entre dois tempos: os tempos do seu e do meu Govêrno, e, entre êles, os 20 anos de vida da Escola e o quarto de século de Brasil depois da guerra.

\section{A MEMória}

A memória do que se passou ao longo dêsse tempo ajuda a compreensão dos objetivos e dos caminhos que êste Govêrno se traçou. Essa memória inspirase na própria presença de Dutra, lúcida testemunha dêsses 25 anos, que o seu Govêrno iniciou.

O Govêrno Dutra marca na História dêste País a restauração e a convalescença da democracia, que a vitória das democracias na guerra impusera no Brasil. Marca o fim dos 8 anos de ditadura, a que haviam levado as contradições e perplexidades dos descaminhos da Revolução de 30 , que, tenente ainda, também ajudei a fazer nas coxilhas dos meus pagos.

Mas o Govêrno que teve a sabedoria de realizar a união da classe politica para restabelecer $o$ processo democrático e governar em paz, haveria ainda de prolongar, pelo refrigério da coalizão, a ilusória viabilidade de uma democracia ortodoxa e saudosista, em um País ansioso por sair do estágio do subdesenvolvimento.
A década de 50 haveria de marcar-se pela passagem da industrialização espontânea à industrialização planejada. A coerência exigia, no campo político, a transição da liberal democracia para a democracia social. A falta de compatibilidade, entre a continuidade do liberalismo político de então e as tensões sociais, seria um dos fermentos das crises politico-militares que se repetiriam a partir de 1954.

Agravariam essas crises a mudança intempestiva da capital e o esfôrço desenvolvimentista realizado sem a cobertura de uma ponderável reserva de divisas que assegurasse a importação dos equipamentos indispensáveis à implantação das indústrias de base.

Os primeiros anos 60 caracterizariam a exaustão econômico-financeira dos esforços da década anterior e o generalizado desencanto pelos caminhos do liberalismo político. A espiral inflacionária gerada por aquela exaustão e a falta de solução para os problemas de natureza econômica acenderiam as crises sociais. No alto, os governantes buscavam munir-se de plenos podêres; na base, soprava-se a neurose de um reformismo que, tantas vêzes, não sabia o que reformar, como reformar e para que reformar, enquanto alguns segmentos da opinião popular se deixavam seduzir pelo chamamento para aventuras políticas contrárias à nossa filosofia de vida.

A decisão da maioria do povo brasileiro no apêlo à intervenção das Fôrças Armadas desencadearia um nôvo passo em nossa evolução democrática que, embora ainda não esteja perfeitamente definido, já se sabe haver sepultado um liberalismo político incompatível com as vio- 
lentas mudanças das estruturas sócioeconômicas.

$\mathrm{E}$, nos dois primeiros Governos da Revolução de março, o País participou da regeneração de nossa vida econômico-financeira, enquanto parcelas da classe política, desatentas à realidade dos tempos e por demais apegadas às filigranas do velho jôgo político, tentavam voltar ao passado.

Nas imagens dêsse rápido retrospecto, forçoso é reconhecer o papel dos 20 anos da ESG no amadurecimento de uma consciência dos novos tempos, que não se perdesse na apreciação exclusiva de determinado aspecto da problemática nacional, mas que tivesse maior amplitude na integração dos quatro campos do poder.

Nestes 20 anos, aqui surgiu uma filosofia de segurança ajustada à de desenvolvimento; aqui se ajudou a criar a mentalidade de planejamento, de programação e de orçamentação que está modificando o panorama dêste País e trazendo ao povo a confiança na gestão da coisa pública.

\section{O QUE FAZER}

A atual denominação da ESG hoje soa imprópria e desadequada, porque primeiro se pensou fazê-la simples curso de alto comando, finalidade que a vivência dêsses 20 anos de muito ampliou. Acabou sendo instrumento, dos mais efetivos, da integração das Fôrças Armadas e de identificação entre civis e militares.

Suas vigílias de todo êsse tempo acordaram uma consciência civil dos problemas nacionais, igualmente atenta aos imperativos da liberdade, do desenvolvimento e da segurança, sem que ninguém possa contestar-lhe a presença reitora no ensaio de uma metodologia de exercício do poder.

Creio que a Escola Superior de Guerra está suficientemente amadurecida para que possa prestar uma contribuição ainda mais efetiva no sentido do aperfeiçoamento de nossos homens públicos, constituindo-se em verdadeira escola de estadistas.

Quero-a como centro de pesquisa aprofundado na realidade brasileira, para que não se desviem tempo e idéia do que é nosso.
Quero-a menos preocupada com conceituações teóricas, com metodologias e sistemáticas, e muito mais empenhada na elaboração de projetos reais e objetivos, que se ofereçam como subsídio aos responsáveis pelo equacionamento e pela solução dos problemas.

Dela espero formulações viáveis de desenvolvimento regional integrado, de iniciativas de natureza tecnológica e científica, de reformas educacionais, de campanhas sanitárias, de projetos agrários, de exploração das riquezas do mar, de educação para a democracia, de erradicação do analfabetismo, de sugestões de alcance geopolítico, capazes de acelerar a integração e o progresso de áreas subdesenvolvidas de nosso País.

Quero-a como laboratório que pesquise problemas de informática para a administração, de estratégia de segurança interna, de comunicação social e de evolução das instituições políticas.

O retrospecto do que se passou, entre - Govêrno Dutra e o comêço do meu Govêrno, do que a ESG logroú fazer e a mençã̉o ao que espero desta instituição, preparam a compreensão de meus propósitos nos quatro anos que hão de vir.

\section{OS OBJETIVOS}

Sei que todos desejam saber quais os objetivos definidos pelo $3 .^{\circ}$ Govêrno da Revolução e, em conseqüência, que políticas e estratégias pretende adotar, para alcançá-los.

A principal dificuldade nas nações que, ao longo dêste século, lutam por emergir do subdesenvolvimento, nesta hora em que 0 avanço científico e tecnológico, em lugar de facilitar-lhes a arrancada, mais aumenta a brecha que nos separa, está precisamente em que seja alcançado o estágio de desenvolvimento sem sacrificio total das liberdades.

E embora nestes tempos não se conheça o exemplo de uma só nação que haja conseguido emergir do subdesenvolvimento sem fazer êsse sacrificio, a firme e determinada opção da Revolução brasileira é a de provar, pela primeira vez, a viabilidade dêsse caminho.

Assim sendo, desejo definir aquêles objetivos nacionais que considero prioritários no meu Govêrno. Quero referirme, primeiro, à concentração de esforços no sentido de que seja alcançado um ritmo de desenvolvimento acelerado e sustentável. Busco a compatibilidade 
dêsse esfôrço desenvolvimentista com a estabilidade interna, consubstanciada na segurança. E procurarei alcançar êsse desenvolvimento e essa segurança com a construcão de uma sociedade politicamente aberta, que concilie a necessidade da aceleração do desenvolvimento com a manutenção das liberdades e com o maior grau possível de privativismo e de decentralização do poder econômico. $\mathrm{E}$ também considero altamente prioritário o objetivo de valorização do homem brasileiro, pelo fortalecimento de suas energias morais e cívicas, assim como pelo aumento de sua renda per capita, de forma a que, no mínimo, possa estar dobrada em 1980.

Mas o desenvolvimento, a estabilidade, a liberdade política e o alto nível de vida não constituem objetivos completos para uma nação, como o Brasil, taihada para a grandeza, se mantidas não forem a independência e a soberania.

$\mathrm{E}$, assim completando, quero sintetizar os objetivos prioritários de meu Govêrno como sendo os de conquistar e manter o desenvolvimento, com segurança, liberdade, independência e respeito ao homem.

Trata-se, então, de ajudar a construir, no Brasil, a sociedade desenvolvida, democrática, independente e livre, assegurando, assim, a viabilidade econômica, social e política do País.

\section{OS CAMINHOS}

Passo, agora, a apresentar algumas idéias sôbre como pretende o meu Govêrno alcançar êsses objetivos. Desejo ressalvar, porém, que não vou mostrar à Escola nenhum dos documentos formais prevístos pela doutrina aqui ensinada e orientadores da política e da estratégia nacionais.

Aqui não venho revelar as Bases para a Política Nacional, consideradas pela Constituição vigente, em seu art. 89, como sendo da competência do Conselho de Segurança. Não venho dizer o Conceito Estratégico Nacional, nem mesmo quero antecipar a estratégia de desenvolvimento de meu Govêrno, que ela estará consubstanciada no Plano Nacional de Desenvolvimento, a ser encaminhado ao Congresso Nacional.

Venho, isto sim, numa homenagem a esta Escola, e como motivação básica para os seus trabalhos dêste ano, tãosomente raciocionar em voz alta sôbre alguns aspectos a serem apreciados na formulação da política e da estratégia do $3 .^{\circ}$ Govêrno da Revolução, raciocínio que farei me valendo da ordenação metodológica dos quatro campos convencionais do poder.

\section{CAMPO ECONÔMICO}

Como a grande meta é o desenvolvimento, começarei pelo campo econômico. Aí estará, precisamente, a maior novidade da nova política governamental. Desde os anos de 50, nosso esfôrço desenvolvimentista vem sendo predominantemente industrial, de forma desequilibrada em relação ao setor agrícola, a ponto de nos defrontarmos hoje com uma taxa de crescimento da produção agrícola da ordem de $4 \%$, enquanto a taxa de crescimento industrial chega a ser três vêzes maior.

Dessa forma, nossa política de desenvolvimento, considerado o campo econômico, visará ao incremento substancial da produção agrícola e ao aumento das exportaçốes, o que certamente haverá de motivar rápida ampliação do mercado interno e induzirá a própria expansão do setor industrial.

Buscaremos, assim, alcançar o crescimento mais equilibrado, ampliar e distribuir melhor a renda nacional, bem como fortalecer o mercado interno, de tal forma a poder absorver, em plenitude, os frutos de nosso surto industrial.

Por outro lado, esperamos incrementar ainda mais as nossas exportações a fim de fortalecer a capacidade de importar os equipamentos indispensáveis à implantação de uma tecnologia atualizada e de afastar os desequilíbrios externos já experimentados, trazendo ao País tôdas as vantagens da integração com uma economia mundial extremamente dinâmica.

Ao definir uma nova política desenvolvimentista no campo econômico, justo é que se recorde o extraordinário salto que a Revolução logrou dar. Assim é que nos idos de março, o produto nacional estava abaixo da taxa de aumento da população e o surto inflacionário atingira índices sem precedentes, calamitosos até.

Nestes seis anos de ação inflexível em favor do futuro do Brasil, logramos o milagre de reduzir a inflação quatro ou cinco vêzes menos, aumentando simultâneamente o ritmo de nosso crescimento, ao ponto de chegarmos à taxa entre 7 e $9 \%$. 
Aceleramos a exploração industrial, principalmente a produção de aço, de navios, de veículos e de cimento. Iniciamos a exploração do xisto, ao tempo em que intensificamos a extração do petróleo, diversificamos nossos esforços no campo da petroquímica e começamos a batalha das pesquisas minerais.

Por outro lado, muito se ampliou nossa capacidade de produção energética, alargou-se de forma impressionante a rêde nacional de estradas e ingressamos na era das comunicaçóes, com a implantação dos mais modernos sistemas eletrônicos.

Quem não se recorda da lamentável situação a que haviam chegado os portos brasileiros? Quem não se recorda do descalabro de nossa Marinha Mercante? Portos e navios, como também o sistema ferroviário, estavam tomados pela insânia demagógica, pela mentira salarial e pela completa anarquia administrativa. Os navios apodreciam nos portos, tornando ainda mais ocioso o pessoal excessivo e pago sem justos critérios de produtividade. As companhias estrangeiras cancelavam suas escalas nos portos brasileiros, onde sofriam tremendos prejuízos diante das greves impostas por uma estiva insaciável mas dócil aos cordões do comando da agitação sindical.

Constate-se, seis anos depois do vendaval, o quadro de reorganização e reaparelhamento de nossos portos e de nossa Marinha Mercante. Observe-se que na faixa portuária não há mais aquêle triste espetáculo da exploração do homem pelo homem, quando os sindicalizados eram os falsos estivadores, que recebiam a paga e davam a propina ao cavalo humano alugado para transportar-lhes a carga.

Seis anos depois, estamos recuperando a Marinha Mercante e os portos, ampliando a construção naval, vencendo a guerra dos fretes e levando às conferências internacionais a nossa constante reivindicação de reciprocidade.

Graças a estabilidade interna, ao planejamento econômico, à austeridade da ação administrativa, ao combate aos desperdícios, aos esforços sérios sem sacrifícios desnecessários, à fixação de prioridades, ao estímulo ao privativismo, ao esfôrço no sentido de maior produtividade, à manutenção dos níveis de salários, de crédito e de tributos consonantes com as exigências de ordem técnica, de eficiência empresarial e de justiça so- cial, restauramos a nossa economia e estamos em condições de acelerar o processo de nosso desenvolvimento econômico. Provas incontestáveis são o crédito econômico do Brasil no exterior, a redução da taxa inflacionária a niveis mais suportáveis, a elevação da taxa de crescimento e a exportação anual superando os 2 bilhões de dólares.

Entretanto, apesar dêsse esfôrço revolucionário de seis anos, quando nos voltamos para a realidade das condições de vida da grande maioria do povo brasileiro, chegamos à pungente conclusão de que a economia pode ir bem, mas a maioria do povo ainda vai mal.

Tenho recebido muitas manifestações no sentido de serem criadas condições mais favoráveis de tributação, de crédito, de salário-mínimo e de indice de custo de vida. Essas condições não podem ser atingidas apenas por decreto, mas conquistadas pelo trabalho em que todos estamos empenhados, sem perder de vista o objetivo principal, que é a aceleração de nosso desenvolvimento.

Com a ajuda de todos os brasileiros, haveremos de prosseguir essa verdadeira revolução operada no campo econômico, completando a reformulação do sistema bancário, das instituições financeiras e do mercado de capitais, iniciada em março de 1964.

$\mathrm{E}$ haveremos de aperfeiçoar ainda mais a legislação revolucionária que, pelo Impôsto de Circulação de Mercadorias, levou recursos substanciais ao município, sangue, vida e energia a tôdas as células do corpo do País, num processo de dinamização do tipo mais efetivo de federalismo, que é o federalismo econômico.

Com a nossa determinação e com a participação efetiva do povo, esperamos acelerar a marcha do desenvolvimento em ritmo de crescimento da ordem de $10 \%$, aumentando a taxa de investimento de 15 para $20 \%$ e reduzindo ainda mais o ritmo já atenuado da inflação, num esfôrço para romper descencionalmente a barreira dos $20 \%$ e situá-la, mais estàvelmente, na casa dos $10 \%$.

$\mathrm{E}$ pretendemos alcançar êsses objetivos, de forma a equilibrar os desniveis setoriais e regionais, a dignificar a moeda, a desenvolver a mentalidade de poupança, a criar novas fontes de produção e de trabalho, e a aumentar significativamente a renda nacional, contribuindo 
para reparti-la com maior justiça por todos os brasileiros.

Quando nossas fontes de energia e de riqueza mineral estiverem pesquisadas e aproveitadas, quando as rêdes de comunicações, e de transportes tiverem as dimensỗes nacionais, e quando nossas riquezas potenciais forem bens na mão de nosso povo, teremos um patrimônio econômico na dimensão mesma de nossos patrimônios moral, geográfico e humano.

\section{CAMPo POLfítico}

Desejo, agora, apresentar algumas idéias relativas ao campo político, nos seus aspectos externo e interno.

Quero afirmar que no centro de tôdas as considerações referentes à política de relações exteriores, predominará sempre o interêsse nacional.

Com base nesse principio inarredável, traçamos os círculos concêntricos de nossas relações internacionais, nas realidades de que somos latino-americanos e de que participamos da América, do Hemisfério Ocidental, da civilização cristã, da democracia, da comunidade de povos de língua portuguêsa e do mundo subdesenvolvido.

Formamos entre os membros da Organização dos Estados Americanos e da Organização das Nações Unidas, empenhados nos melhores propósitos de assegurar a paz e a concórdia entre os povos, mas também determinados a contribuir para que os avanços científicos e tecnológicos beneficiem tôda a humanidade e para que o imperativo da justiça social não prevaleça apenas entre os homens, mas sobretudo entre as nações.

Somos solidários com os justos anseios dos povos latino-americanos, como de resto com os povos subdesenvolvidos de outros continentes, na busca de condições mais justas para o comércio internacional e de uma politica de royalties mais humana, mais aberta, mais universal.

Formaremos sempre entre aquêles que procurarão sensibilizar os países de grande desenvolvimento no sentido de que se dêem conta dos graves perigos que ameaçam a humanidade inteira no agravamento dos desníveis sócio-econômicos entre os povos, em plena era da comunicação. Os que hoje tanto se chocam com as desigualdades sociais, nos países dos outros, devem meditar na de- sigualdade maior e mais ameaçadora, que é a desigualdade entre as nações. $\mathrm{E}$, com essa compreensão, insistiremos na validade do princípio de que não haverá têrmo para a crise do sistema monetário mundial, sem que, simultâneamente, seja levada avante a idéia da criação de fundos para o desenvolvimento de dois terços da humanidade.

E certo que a última razão, quando da tomada de nossas decisões no campo da política externa, no conflito dos interêsses das comunidades a que estamos ligados, será sempre a projeção do autêntico interêsse nacional. E certo que todo esfôrço do Brasil no trato com as outras naçôes será sempre no sentido do imperativo do desenvolvimento nacional. certo que a formulação e a execução de tôda a nossa política externa, desde a mais alta formulação governamental na Praça dos Três Podêres até a ação silenciosa de um distante funcionário consular em um confim do mundo, serão sempre voltadas para o bem de nosso povo.

Tudo isso é certo, tudo isso terá de meu Govêrno tôda a atenção, mas o Govêrno e o povo do Brasil, que têm pressa de acelerar o seu desenvolvimento, não aspiram a ver êste País desenvolvido, próspero e feliz, em meio a um mundo em que existam nações cada vez mais carentes, mais pobres, mais dessangradas. É que o Brasil não deseja chegar às etapas superiores do desenvolvimento visando ao desfrute de qualquer forma de hegemonia ou de domínio, mas para alcancar a felicidade de seu povo e para contribuir para a vinda de melhores dias para tôda a humanidade.

\section{ASPECTOS INTERNOS}

Volto-me, agora, para os aspectos internos do campo político, onde, quase sempre, cada palavra se transforma em manchete, enquanto outras decisões, de repercussõ̉es profundas na vida de todos nós, ficam despercebidas e sem eco.

Em recente entrevista aos jornalistas credenciados junto ao Palácio do Planalto, tive oportunidade de tornar bem claro o meu pensamento sôbre o processo de atingimento do que havíamos chamado de plenitude democrática. Falando àqueles profissionais da imprensa, fiz, com a nação inteira, o prometido jôgo da verdade.

Não tive o propósito de crestar a esperança, mas de ser realista, de alertar os açodados e de dar a cada um o seu 
quinhão de responsabilidade na obra coletiva. Estou seguro de que a esperança e a fé não prosperam na ilusão, na mentira e no engôdo, mas sim na verdade e na lealdade.

Reitero que a Revolução proporcionou ao Govêrno os podêres e os instrumentos necessários para ação positiva e eficiente. Reitero que usarei êsses podêres e instrumentos extraordinários do Executivo exatamente para criar aquelas condições em que êles possam ser dispensáveis. Assim como não os usaremos indiscriminadamente, também, precipitados, não renunciaremos a seu emprêgo. o Estado Revolucionário durará o tempo indispensável à implantação das estruturas política, administrativa, jurídica, social e econômica capazes de promover a integração de todos os brasileiros aos niveis mínimos de bem-estar.

\section{ELEIÇóES}

Considero êste ano e o próximo decisivos para nossa vida política. É que nêles se vão eleger e instalar os novos chefes dos podêres executivos estaduais e os novos representantes do povo nas câmaras legislativas.

Não posso omitir-me em assunto de influência vital para o meu Govêrno, pois as administraçốes federal, estaduais e municipais devem constituir um todo coordenado e harmônico. Confio em que os partidos políticos - e eu usarei minha parcela de influência no âmbito do meu próprio - apresentem ao povo, ou aos seus representantes, nomes dignos de exercerem a delegação de sua vontade, a fim de que os melhores cheguem ao poder. Confio em que a eleição que se aproxima seja, de tôdas, a mais marcada pelo sentido de renovação, aliado à experiência bem sucedida, cujo exemplo eu mesmo venho dando no rejuvenescimento de meu Ministério.

Reitero que todo brasileiro tem o direito de fazer oposição ao Govêrno. Considero imprescindível ao bom funcionamento do regime a existência de opositores. Por isso mesmo não serei hostil aos que de mim discordarem. No meu Govêrno não houve, não há, nem haverá coação por motivos puiramente políticos.

Mas, também, não haverá impunidade para atos de violência e de perturbação da ordem, que contrariam o nosso espírito cristão, ferem nossas tradições de evolução pacífica e só abrem caminho para soluções de fôrça. O caminho da liberdade é o caminho da lei.
Quero dizer uma palavra sôbre a efetivação da mudança da capital. Hei de torná-la realidade. um duro legado que a Revolução recebeu e que tem procurado consolidar como se fôsse obra sua. Estou convencido da necessidade de acelerar a conclusão da mudança, mesmo que isso ainda tanto nos sacrifique, para assegurar o pleno exercício do Govêrno em Brasília.

Empenho-me em acelerar a mudança para que se antecipe a vinda dos proveitos da transformação de um êrro tático num grande êxito estratégico. Trata-se de fazer com que aquela decisão que, em curto prazo, gerou tantos males sociais, possa, em prazos médio e longo, trazer seus inegáveis benefícios à obra de integração nacional.

\section{CAMPO PSICOSSOCIAL}

Disse antes que considero altamente prioritário o objetivo de valorização do homem brasileiro. Quero agora levantar algumas idéias sôbre como vejo essa valorização.

O primeiro caminho para a valorização do homem brasileiro é a integração de todos ao esfôrço nacional.

Em mensagem dirigida à SUDENE, no $10.0^{\circ}$ aniversário de sua criação, disse e reitero agora que meu Govêrno pretende orientar sua política no sentido da prevalência do nordestino sôbre o Nordeste.

Quero significar com essa afirmação que considero o homem anônimo a primeira das nossas infra-estruturas básicas. Cabe ao Govêrno mobilizar todos os recursos e convocar tôda a gente para que essa seja em verdadie a mais sólida de tôdas as nossas estruturas.

Por isso é que começo pelo campo. É que no campo está a maioria de nós mesmos. É que do campo vem a nossa alimentação, e do campo sai a parte mais valiosa de nossa pauta de exportação. Dando prioridade ao campo, estou dando prioridade à valorização do homem brasileiro.

Confio em que as medidas de amparo e de incentivo que estou tomando e que ainda virei a tomar em favor das atividades agropecuárias, além de intensificarem o crescimento da produção agrícola, haverão de contribuir para a integração do interior, para o abastecimento das cidades e para a melhoria do custo de vida.

Mas também estarei permanentemente atento ao trabalhador urbano. Sendo a 
Revolução de março marcada sobretudo pela coragem, da austeridade e pelo combate intimorato à inflação, não lhe foram prometidas vantagens demagógicas e ilusórias. Mesmo assim, é justo que se apontem iniciativas, que apoiaremos com tôda a energia, de grande valor para o assalariado, algumas até ainda não perfeitamente reconhecidas, como o Plano Nacional de Habitação, o Fundo de Garantia, a correção monetária dos débitos salariais e a unificação da Previdência Social.

Procuraremos aperfeiçoar êsses instrumentos, criaremos outros e nos dispomos a tornar efetivo o preceito constitucional de integração dos trabalhadores "na vida e no desenvolvimento da emprêsa, com participação nos lucros e, excepcionalmente, na gestão."

Acredito que todos já tenham sentido que o problema da educação nacional deixou de ser cuidado, menos por palavras, e mais com decisốes e com recursos.

\section{EDUCAC̃̃O}

Sem precisar mencionar o grande esfôrço dos anteriores Governos revolucionários, que tornou o orçamento federal da educação, pela primeira vez, um orçamento substancial, que aumentou as oportunidades educacionais em todos os niveis e que erradicou a subversão das escolas, tornadas agora um lugar de estudos e pesquisas, aí estão, como providências concretas, a retomada das obras da ilha do Fundão, a revisão dos níveis salariais do professor e a reorganização do Ministério da Educação e da Cultura.

Dentro em breve estaremos realizando uma grande campanha de alfabetização e iniciando as obras de construção, em diferentes partes do território nacional, de mais de duas dezenas de ginásios voltados para o trabalho.

Simultâneamente, estaremos ampliando e aperfeiçoando o sistema universitário, instaurando centro de pesquisa e estimulando o advento de uma mentalidade tecnológica e científica indispensável à formação de um know how brasileiro.

Em favor da educação de nosso povo aceitamos a ajuda internacional, venha de onde vier, desde que não nos sejam impostos condicionamentos lesivos à nossa dignidade e à liberdade de orientarmos a formação de nossos jovens segundo nossos padrões morais e as nossas próprias concepções de vida.
Cuidados especiais estaremos sempre dando à família e à formação moral e cívica do homem brasileiro, de tal forma que se preservem os valôres espirituais da nacionalidade e se fortaleça o caráter do povo, sem o que o progresso material poderá ser passageiro, enganador e até desumano.

\section{SAÚDE}

Disse antes que a saúde é um dos setores prioritários de meu Govêrno. Para substituir, à frente do Ministério específico, o grande nome da medicina brasileira, fui buscar um pesquisador, um cientista, um profundo conhecedor de sua problemática. Confio em que, convenientemente estruturado, venha aquêle nôvo Ministério a ser, em curto prazo, instrumento efetivo do esfôrço governamental em favor do homem brasileiro.

\section{FUNCIONALISMO}

Pretendo dar especial atenção aos trabalhadores do Govêrno, àquela parcela de quase um milhão de brasileiros que vive dos salários que a Fazenda Pública pode pagar. Quero referir-me ao funcionalismo, quase sempre entregue às alternativas do esquecimento ou da demagogia cúpida que lhe disputa os favores. "Haveremos de valorizá-lo, dignificando sua missão". Há nesse campo tôđa uma revolução a fazer, de forma que a máquina burocrática possa de fato responder ao que dela se solicita.

Cursos de formação, de especialização, de aperfeiçoamento, de pós-graduação; cadastramento; revisão da legislação; justiça salarial; informática e incentivo à produtividade são alguns tópicos dessa revolução que teremos de fazer no campo do pessoal. Sem ela não chegaremos jamais a redimir o funcionário no conceito do povo e continuaremos a ter por muito tempo ainda o triste espetáculo de tantas leis que não chegam a sair do papel.

\section{COMUNICAÇÃO}

Abordando os aspectos psicossociais, quero referir-me, finalmente, ao esfôrço de comunicação do Govêrno. Desde a primeira hora de minha presença na cena nacional, convoquei a participação de todos. Quero que todos tragam a sua palavra, a sua sugestão, a sua idéia, a sua contribuição construtiva. E, por outro lado, que me ouçam nas minhas razões e me compreendam nos meus objetivos. Mas é preciso também dizer bem 
claro que a intriga e a injúria não contribuem, como não contribuem o cantochão do empreguismo, a bajulação, a contestação e o irrealismo.

Valendo-me dos modernos meios de comunicações que a Revolução de março trouxe e que hoje já permitem a identificação de quase todos os brasileiros, estarei sempre presente à casa de cada um para dizer a todos a verdade, e somente a verdade.

Não farei promoção pessoal, nem permitirei que a façam à minha sombra. A comunicação social de meu Govêrno visa a informar-se, a informar, a divulgar e a educar. Usarei os instrumentos a meu alcance para o chamamento de todos à coesão, ao respeito à lei, à produtividade, à união, à esperança. Usarei êsses instrumentos para mobilizar a vontade coletiva para a obra do desenvolvimento nacional.

Deixo bem claro que não espero unanimidade em tôrno da administração, o que seria incompatível com o regime democrático. Espero apenas que, tôdas as vêzes em que estiverem em jôgo os supremos valôres da liberdade, do desenvolvimento e da segurança compreendamos que a pátria é uma só.

\section{CAMPO MILITAR}

Chego, enfim, à área específica de preocupações desta casa, chego à área da segurança. Sabem todos que não é mais um problema privativo das Fôrças Armadas.

Bem sabemos que, no passado, ameaças e perigos - externos e fronteiriços raramente afetavam a nação como um todo, configurando-se a resposta no quadro de distante e epidérmica defesa nacional.

Mas o avião primeiro, e, depois, as armas psicológica e nuclear, assim como o caráter predominantemente ideológico dos antagonismos entre os povos, tiraram a nitidez das fronteiras entre a paz e a guerra, aprofundaram as ameacas ao coração das nações e à mente dos homens, passando-se ao contexto abrangente da segurança nacional.

Prevê-la e provê-la na dimensão e na intensidade justas, adequadas ao valor das ameaças e à impulsão no sentido do progresso, é dever inarredável do Govêrno.
Porque sei que a segurança de uma comunidade ou de um povo não prospera na desigualdade entre os homens, na floração dos privilégios, na injustiça social, na desagregação entre as classes, entre as raças, entre as gerações, meu objetivo primeiro e último é o desenvolvimento nacional.

Mas preciso advertir que a segurança interna de uma nação se faz mais onerosa, mais dura, mais sofrida, quando do desrespeito à lei, quando da libertação dos instintos, do desafio da violência destruidora e da escalada solerte da contestação a tôda forma de autoridade.

E aqui me faço solidário com todos aquêles que, no anonimato e com o risco da própria vida, agentes injustiçados da segurança dêste País, enfrentam, de peito aberto, a contestação, a violência, a libertação dos instintos, o desrespeito à lei. Graças aos seus sacrifícios, estamos vencendo o terrorismo de minoria enganada pela falácia de sistemas de vida incompatíveis com a índole de nossa gente e vislumbramos já a total normalização da vida nacional.

Convencido de que a segurança é a paz e entendendo, com Santo Agostinho, que ela é a tranqüilidade na ordem, quero dizer à Nação - que de mim só espera o meu dever - tudo farei para curar, nas raízes, as causas velhas e profundas de justas inquietações, angústias e aflições.

Mas quero dizer também, que, no atendimento da ordem, da tranqüilidade e da paz; contra o terrorismo importado; contra o terrorismo - sombra, eco e parcela de um processo universal de desagregação; contra o terrorismo, que desconhece qualquer forma de consideração pelos direitos humanos; e até que esteja seguro de que êle não mais perturba 0 esfôrço nacional pelo desenvolvimento, usarei, em plenitude e com tôda a firmeza, os podêres que a Constituição, que prometi defender, coloca em minha mão.

E, se me disponho assim a enfrentar a contestação, sinto que a forma mais duradoura de segurança só se afirma na igualdade, na liberdade, na justiça, no amor e na integração dos homens e, por isso, cuido de alcançá-la pela concentração prioritária de recursos no campo educacional, por um esfôrço de comunicação com a consciência de todos os homens válidos de minha terra, no apêlo à 
confiança coletiva e no fortalecimento do caráter nacional.

Pensando em segurança, penso nas Fôrças Armadas, e no Exército, que é a minha própria vida. Conheço os problemas da minha Fôrça e das Fôrças suas irmãs. E conheço a problemática das Fôrças Auxiliares e da Polícia Federal. Todos são instrumentos do mesmo ofício da segurança. Velarei para que êsses instrumentos valham sempre mais, pelos seus meios materiais e humanos.

Buscarei atendê-los, nas necessidades prioritárias de reequipamento, visando ao cumprimento dos deveres institucionais e dos compromissos revolucionários, assim como de colaboração com outros setores, na medida de suas possibilidades e sem prejuízo de suas tarefas profissionais.

Penso que contribuir para o reaparelhamento dessas Fôrças é tarefa patriótica indispensável à nossa segurança e, conseqüentemente, ao atingimento de todos os nossos objetivos prioritários.

\section{IDENTIFICAÇÃO COM DUTRA}

$\mathrm{E}$ aqui volto a me identificar com 0 Presidente a quem entregarei a medalha comemorativa dos vinte anos desta casa, volto ao confronto com o grande Presidente Dutra, a cujo pulso deve a nação haver repelido por duas vêzes o assédio da subversão totalitária: a rebelião nos quartéis em 35 e a rebelião nas ruas em 47, quando do fechamento do Partido que se valia das franquias democráticas para destruir a democracia.

Diante do Velho Chefe, nesta casa, e perante a nação, inspiro-me na sua austeridade, na sua coragem e na sua firmeza para bem cumprir minha missão. E também me inspiro no seu amor à lei, na sua compreensão e no seu chamamento à união.

Dutra buscou a união da classe política para restaurar a democracia. Que Deus me ajude, no seu apêlo à união de tôdas as classes, para que eu possa ajudar a construir no Brasil a sociedade desenvolvida, democrática, independente e livre." 